\title{
Coverage and focus of a cervical cancer prevention program in southern Brazil
}

\author{
Carlos Alberto Temes de Quadros, ${ }^{1}$ Cesar Gomes Victora, ${ }^{1}$ \\ and Juvenal Soares Dias da Costa ${ }^{1}$
}

Suggested citation Quadros CAT de, Victora CG, Costa JSD da. Coverage and focus of a cervical cancer prevention program in southern Brazil. Rev Panam Salud Publica. 2004;16(4):223-32.

ABSTRACT Objective. To determine the coverage and focus of cervical cancer screening (Pap smears) in a population-based sample in Brazil.

Methods. Cross-sectional cluster survey covering 1730 women aged 20 years or older with a history of sexual activity. Information was collected on social, demographic and behavioral variables, knowledge of and use of the Pap test.

Results. Of women aged 25-59 years, who are the target population of the national cervical cancer screening program, $78.7 \%$ had had at least one Pap test in their lifetime, and $68.8 \%$ had had a Pap test in the last 3 years. Statistics for focus of the program showed that of the 637 women who reported having a Pap test in the last year, only $20.6 \%$ actually required one. The remainder were either outside the age range or had had another test less than 30 months previously. Prevalence of not having been tested in the previous 3 years was highest among black $(41.7 \%)$ and low-income women (64.3\%), and among those at greatest risk for cervical cancer $(62.3 \%$ for women with three or more risk factors). Focus was inversely related to socioeconomic status.

Conclusion. Coverage rates were similar to those reported in other national studies, but this is the first report to examine the focus of the national program. We show that 8 of every 10 Pap tests were not necessary. Coverage levels remain unacceptably low among women of low socioeconomic status and those at greatest risk for cervical cancer.

Key words Papanicolaou smear; vaginal smear; physical examination; cross-sectional study; epidemiology.

Invasive cervical cancer is ranked second in incidence among malignant neoplasms in women worldwide. In 2000, 468000 new cases and 233000

\footnotetext{
Programa de Pós-graduação em Epidemiologia, Faculdade de Medicina, Universidade Federal de Pelotas, Pelotas, Brazil. Send correspondence and reprint requests to: Carlos Quadros, Tobias da Silva 99 cj. 402, CEP 90570020 Porto Alegre, RS, Brasil; telephone: (55) 51 32220923; fax: (55) 51 32220923; e-mail: cquadros@via-rs.net
}

deaths occurred globally, representing approximately $10 \%$ of the global cancer incidence and mortality among women. Incidence is highest in less developed areas, and mortality represents roughly $50 \%$ of the overall incidence $(1,2)$. In Brazil mortality rates are high because diagnosis and medical care are often sought too late (3). Moreover, mortality rates due to this disease are increasing: in 1979, the ageadjusted rate was 3.4 per 100 000; in
1999, it was 4.7 per 100000 (4-6). This trend does not seem to be due solely to improvements in case notification, but to an actual increase in mortality.

The natural history of cervical cancer is characterized by the slow development of precancerous lesions (7) that may be detected at an early stage $(8,9)$. The effectiveness of Papanicolaou smears was confirmed by organized screening programs in several countries $(10,11)$. Organized programs are char- 
acterized by central coordination and data collection, a well-defined target population, contacts with individual patients-including the active search for women who failed to attend appointments-and well-defined intervals between examinations. There has been much debate as to the costs and benefits of programs of this magnitude, most studies agreeing that the benefits provided by such a policy justify its implementation $(12,13)$. Although there are no randomized clinical trials that provide evidence of the effectiveness of screening for cervical cancer with Pap smears, observational studies of different designs have confirmed the effectiveness of organized programs. Ecological studies in British Columbia, Canada, showed that $80 \%$ coverage of the target population was achieved, resulting in a $70 \%$ reduction in incidence and mortality (14-16). Supportive evidence is also provided by data from Finland (17-18) and from Denmark (19).

The low levels of efficiency and effectiveness of some cervical cancer prevention programs have been attributed to low population coverage and to the poor quality of services provided. In the state of Rio Grande do Sul, in southern Brazil, time trends for cervical cancer follow the national pattern of a gradual increase in mortality (20), which suggests deficiencies in prevention.

In Brazil, the National Program for the Prevention of Cervical Cancer, launched in 1998, makes use of a mixed opportunistic-organized approach to screening. The program, implemented nationwide, recommends Pap testing every 3 years after two consecutive annual negative tests; the priority age group is $25-59$ years (6). There were two mass campaigns in 1998 and 2002, but most tests take place during routine attendance at public sector health facilities. It should be noted that, although in an ideal world organized screening is the best option, programs that do not have all the components of a fully organized program can nonetheless contribute to reducing mortality if high coverage is achieved.

The present study describes the results of a population-based survey carried out in the city of Pelotas, southern
Brazil, aimed at estimating coverage, focus (proportion of all tests performed that were actually needed) (21), and the determinants of participation in the cervical cancer prevention program.

\section{MATERIALS AND METHODS}

This study was part of a multipurpose health survey carried out by the Universidade Federal de Pelotas Postgraduate Epidemiology Program.

\section{Study design}

A population-based cross-sectional study was conducted in the urban area of Pelotas, with roughly 320000 inhabitants.

\section{Study population}

The study sample consisted of all sexually active women aged 20 years or over. Although the target population of the screening program was restricted to those aged 25-59 years, information on all women was required to estimate the program's focus (see below).

The following variables were investigated: knowledge about the test (Pap smear) and its recommended periodicity; history of any previous tests; time since the last and next-to-last tests. Data were also collected on age, skin color, socioeconomic level (with the Associação Brasileira de Pesquisa de Mercado or ABIPEME system, widely used to classify socioeconomic level from A to $E$ based on ownership of household assets) (22), household income, schooling, marital status, smoking history, medical appointments with gynecologists and general practitioners, type of health care of last appointment, menopausal status, number of normal deliveries, number of sexual partners, and age at first sexual intercourse.

\section{Sampling}

Sampling was carried out in multiple stages. First all 281 census tracts (primary sample units) in urban Pelotas were listed and stratified into four groups according to mean head of family schooling. For each stratum a systematic sample of census tracts was drawn, with the probability of inclusion proportionate to population size. All households in each tract were listed, and systematic sampling was used to identify households that were to be visited. The sample included all women aged 20 years or more living in the selected households.

A structured questionnaire was used, and the interviews were carried out in the women's homes by trained interviewers between February and April, 2002. The questionnaire, designed for a broader study of health care services, consisted of 150 questions, 10 of which referred to the subject of the present study. As a quality control measure one of the investigators (C.Q.) checked the responses in a random subsample of $10 \%$ of the whole sample with a shortened version of the questionnaire. The primary objective of quality control was to ensure that the interview had taken place. It was not possible to calculate the kappa statistic for agreement on knowledge about Pap smears because the initial interview might have had an effect on subjects' level of knowledge.

To estimate a coverage of $65 \%$ with a $4 \%$ margin of error, and allowing for a $10 \%$ nonresponse rate and a design effect of 2.0, sample size was calculated at 1201 subjects. Calculations to study the associations between explanatory variables and coverage assumed a $30 \%$ prevalence of exposure, a 1.5 odds ratio, a coverage of $63 \%$ among exposed women, a 2.0 design effect, and an additional $10 \%$ for nonresponse and $15 \%$ to control for confounders. Assuming 80\% power, sample size was calculated at 1144 women.

\section{Statistical analysis}

Coverage was calculated with two different denominators: all eligible women, and those who reported knowing about the Pap test. Program focus (21) describes the proportion, among all 
tests that were carried out, of those which were actually necessary considering the woman's age and the time elapsed since the last test, in accordance with the national recommendations.

Factors associated with coverage were analyzed for the whole sample, assuming that women who reported not knowing about the Pap test would never have been tested (23).

The initial analyses yielded descriptive information on the subjects' history of previous Pap tests and knowledge about the test and its periodicity in relation to demographic, socioeconomic, and behavior- and healthrelated variables. Next, crude analyses were carried out to determine outcome prevalence according to the categories of independent variables. All outcomes were dichotomous, and we used chi-squared tests for heterogeneity and tests for linear trends in proportions for ordinal independent variables. Adjusted analyses were carried out for the outcome 'not having had a Pap test in the previous 3 years.' These analyses consisted of Poisson regression (svypois procedure, robust variance option, STATA 7.0 software) because-due to the high levels of coverage-odds ratios estimated through logistic regression tend to overestimate prevalence ratios. All analyses took into account the cluster sample strategy. Design effects due to cluster sampling, for the outcomes studied, were 2.1 for not having had a Pap test during the previous 3 years; 2.3 for never having had a Pap test, and 2.4 for not knowing about the test.

Multivariate analyses were based on a three-level conceptual model (24). The most distal level of determination included the variables age (in whole years) and skin color (white or nonwhite, as observed by the interviewer). The second (intermediate) level included variables that may be affected by those in the first level: schooling (in whole years), socioeconomic level (levels A-E), family income (above or below the minimum wage in the preceding month), and marital status (married or consensual union, single, divorced, or widow). The proximal level included variables that may be affected by those in the two higher levels, such as smoking (current smoker, former smoker, nonsmoker), number of vaginal deliveries, number of lifetime sexual partners, age at first sexual intercourse, medical appointments with general practitioners or gynecologists during the previous year, and type of health care (private or public). Menopausal status was included in the model with the distal level variables. The hierarchical approach adjusts the effect of each variable for those in the same or higher levels of causality. In this manner it avoids the pitfall of adjusting distal determinants for possible mediating variables (24). Within each level, variables with $P<0.2$ were kept in the model as potential confounders.

To evaluate the association between cancer risk and having had a preventive Pap test, a numerical risk score was constructed based on the presence of factors known to be related to an increased risk of cervical cancer (18): age at first sexual intercourse below 14 years; four or more sexual partners during the woman's lifetime; four or more vaginal deliveries; less than 5 years' schooling; and smoking. Each of these items was given equal weight in the score, which ranged from zero to five.

\section{Ethical approval}

The study protocol was approved by the Ethics and Research Committee of the Universidade Federal de Pelotas, and confidentiality of individual data was maintained. Only the subjects' verbal consent was requested because the project was considered to entail minimal risk. A leaflet explaining the importance of the Pap test was distributed to all participants.

\section{RESULTS}

The 1600 households sampled contained 3409 persons of either sex over 19 years of age, 3372 of whom were eligible for participation in the study. Persons unable to respond to the ques- tionnaire $(1.1 \%$ of subjects) were excluded. Of the 1880 women more than 20 years old, 72 could not be interviewed $(3.8 \%)$. The final sample comprised 1730 women who were or had been sexually active. The descriptive analysis showed that $83.0 \%$ of the women were white and that $10.4 \%$ received less than the minimum wage; $4.9 \%$ of the women had never attended school and $17.0 \%$ had done so for 12 or more years; $67.3 \%$ of the women were married, $14.0 \%$ were single, and $5.8 \%$ were widows.

Table 1 presents results for the 1198 women aged 25-59 years, the target population of the cervical cancer prevention program. Analyses were also done separately for all women aged 20 years or more, and the results were very similar.

Of the women interviewed, $86 \%$ reported knowing about the Pap test, $78.7 \%$ reported having had the test at least once in their lifetime, and $68.8 \%$ reported having had the test less then 3 years previously.

Among women who knew about the test, only $0.3 \%$ answered correctly that the recommended periodicity was every 3 years, and $91.5 \%$ reported that they had had the test at least once in their lifetime. A total of 637 women had been tested within the previous year (Table 1). An additional 125 women aged under 25 or over 59 years (not included in Table 1) also reported having had a Pap test during the preceding year.

These data allowed us to estimate program focus, that is, the percentage of these women who actually needed to be tested during the preceding 12 months (Table 2). We started by identifying women who had unnecessary tests. These comprised the 125 women who were outside the recommended age group and 438 women who, despite being in the correct age group, had had a previous test during the preceding 30 months (a period of 30 months rather than 36 months was used as a conservative estimate). However, it was necessary to allow for women who were due for their second test, which should be done one year after the first. We estimated this num- 
TABLE 1. Distribution of women surveyed in 2002 in Pelotas, Brazil, according to their knowledge of the Pap test and history of Pap testing

\begin{tabular}{|c|c|c|}
\hline \multirow[b]{2}{*}{ Variables } & \multicolumn{2}{|c|}{$\begin{array}{c}\text { Women between } 25 \text { and } 59 \text { years } \\
\text { of age }(n=1198)\end{array}$} \\
\hline & Percent & Number \\
\hline \multicolumn{3}{|l|}{ All women in the age group } \\
\hline \multicolumn{3}{|l|}{ Knowledge of the test } \\
\hline Yes & 86.0 & 1030 \\
\hline No & 14.0 & 168 \\
\hline \multicolumn{3}{|l|}{ At least one test during the woman's lifetime } \\
\hline Yes & 78.7 & 943 \\
\hline No & 21.3 & 255 \\
\hline \multicolumn{3}{|l|}{ Time elapsed since last test } \\
\hline$<12$ months & 42.7 & 512 \\
\hline $12-23$ months & 17.4 & 208 \\
\hline 24-35 months & 8.8 & 105 \\
\hline$\geq 36$ months & 9.8 & 118 \\
\hline Never been tested & 21.3 & 255 \\
\hline \multicolumn{3}{|l|}{ Women who knew about the test } \\
\hline \multicolumn{3}{|l|}{ Knowledge of periodicity } \\
\hline Does not know & 5.0 & 51 \\
\hline More than once a year & 24.7 & 255 \\
\hline Once a year & 68.6 & 707 \\
\hline Every 2 years & 1.4 & 14 \\
\hline Every 3 years & 0.3 & 3 \\
\hline \multicolumn{3}{|l|}{ At least one test during the woman's lifetime } \\
\hline Yes & 91.5 & 943 \\
\hline No & 8.5 & 87 \\
\hline \multicolumn{3}{|l|}{ Women tested during the last 12 months } \\
\hline \multicolumn{3}{|c|}{$\begin{array}{l}\text { Interval between next-to-last and last test more } \\
\text { than } 12 \text { months before }\end{array}$} \\
\hline$\leq 30$ months & 85.5 & 438 \\
\hline $31-42$ months & 3.1 & 16 \\
\hline$>42$ months or only one test in lifetime & 5.3 & 27 \\
\hline Very first test & 6.1 & 31 \\
\hline
\end{tabular}

ber to be equal to that of women who had their first test, i.e., 31 women. We also allowed for a $6 \%$ rate of repeat tests because of abnormal results (25), i.e., 26 women. Thus, of the 438 women in the target age group, we es- timated that Pap tests were not necessary in 381 (438 minus 31 minus 26).

In summary, of 637 women who had had the test during the preceding year, 125 were outside the target age range and 381 were in the correct age range but did not need a Pap test on that occasion. This gave a total of 131 women, or $20.6 \%$, who actually needed the test. This figure represents the program's focus.

Table 2 presents focus according to ABIPEME socioeconomic level, and shows that roughly $90 \%$ of the tests in women belonging to levels $\mathrm{A}$ and $\mathrm{B}$ were unnecessary. Separate analyses (not shown) for public and private sector users showed focus to be $23.8 \%$ and $18.1 \%$, respectively.

Table 3 presents descriptive statistics for the 1198 women aged 25-59 years and the prevalence of the outcomes for each category of explanatory variables. Bivariate analyses were carried out for the outcomes 'not knowing about the Pap test,' 'never having been tested,' and 'not having been tested in the last 3 years.' Because the results were similar for these three outcomes, they will be discussed together.

In general, the highest rates of knowledge and coverage were observed in the 35-39 and 40-44 year old age groups although the prevalence of 'never having the test' was also low in the 50-54 year old group. Knowledge and coverage were lower among nonwhite women, despite similar proportions of white $(64.2 \%)$ and nonwhite women $(64.7 \%)$ having visited gynecologists during the previous year.

Both knowledge and coverage showed statistically significant direct associations with socioeconomic level, family income and schooling. The strong association of socioeconomic level persisted when the analysis was

TABLE 2. Focus, according to socioeconomic level, of the cervical cancer prevention program in Pelotas, Brazil, in 2002, calculated on the basis of tests performed during the previous year

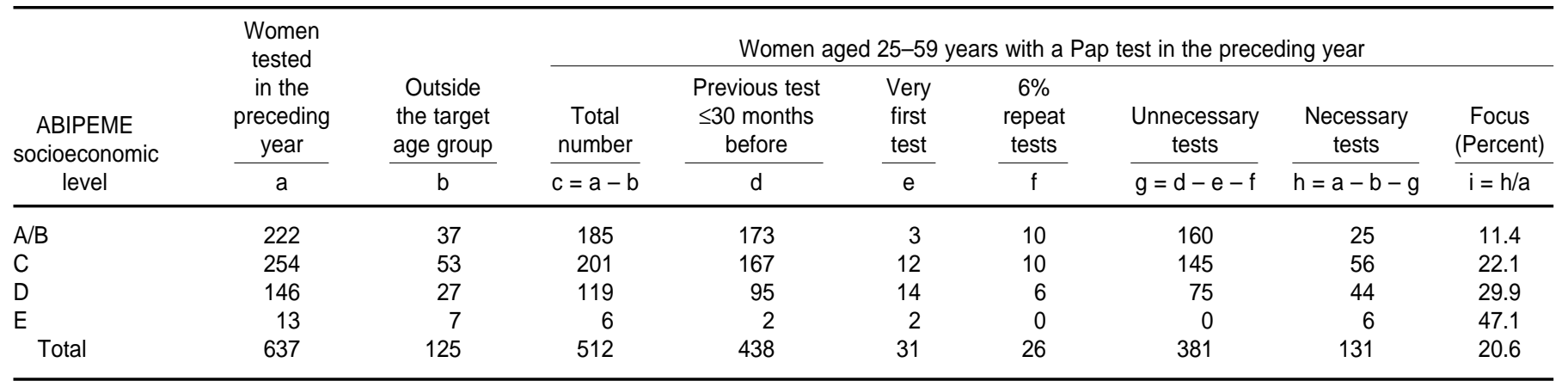


TABLE 3. Distribution of 25-to-59-year-old women in Pelotas, Brazil, in 2002, according to sociodemographic, behavioral and reproductive variables, and association with the prevalence of knowledge about the Pap test and history of Pap testing

\begin{tabular}{|c|c|c|c|c|}
\hline Variable & $\begin{array}{c}\text { Number of } \\
\text { women }^{\mathrm{a}}\end{array}$ & $\begin{array}{l}\text { Prevalence of } \\
\text { lack of knowledge } \\
\text { about the test } \\
\text { (Percent) }\end{array}$ & $\begin{array}{c}\text { Prevalence of } \\
\text { never having } \\
\text { been tested } \\
\text { (Percent) }\end{array}$ & $\begin{array}{l}\text { Prevalence of not } \\
\text { having been tested } \\
\text { in the previous } \\
3 \text { years (Percent) }\end{array}$ \\
\hline Age (years) & & $(P=0.03)^{\mathrm{b}}$ & $(P=0.03)^{\mathrm{b}}$ & $(P<0.009)^{b}$ \\
\hline $25-29$ & 166 & 18.1 & 31.9 & 39.2 \\
\hline $30-34$ & 172 & 15.2 & 21.5 & 29.1 \\
\hline $35-39$ & 182 & 11.0 & 18.7 & 23.6 \\
\hline $50-54$ & 185 & 12.4 & 18.4 & 33.0 \\
\hline $55-59$ & 126 & 20.6 & 23.0 & 38.1 \\
\hline Skin color & & $(P<0.001)^{\mathrm{b}}$ & $(P<0.001)^{b}$ & $(P<0.001)^{b}$ \\
\hline White & 994 & 12.5 & 19.3 & 29.0 \\
\hline Nonwhite & 204 & 21.6 & 30.9 & 41.7 \\
\hline $\mathrm{E}$ & 42 & 38.1 & 54.8 & 64.3 \\
\hline Family income (-fold minimum wage) & & $(P<0.001)^{\mathrm{c}}$ & $(P<0.001)^{\mathrm{C}}$ & $(P<0.001)^{\mathrm{c}}$ \\
\hline$>6$ & 274 & 4.4 & 9.1 & 16.1 \\
\hline 3.01 to 6.0 & 298 & 11.4 & 18.8 & 28.9 \\
\hline 1.01 to 3.0 & 423 & 18.7 & 28.1 & 39.7 \\
\hline$<1$ & 116 & 30.2 & 38.0 & 50.0 \\
\hline Schooling (years) & & $(P<0.001)^{\mathrm{c}}$ & $(P<0.001)^{\mathrm{c}}$ & $(P<0.001)^{\mathrm{c}}$ \\
\hline 12 or more & 203 & 2.5 & 5.9 & 11.8 \\
\hline $9-11$ & 291 & 7.6 & 17.2 & 24.4 \\
\hline $5-8$ & 411 & 13.9 & 21.9 & 31.6 \\
\hline $1-4$ & 243 & 25.5 & 32.1 & 46.1 \\
\hline Never smoked & 633 & 13.6 & 21.2 & 28.6 \\
\hline Former smoker & 217 & 12.9 & 16.1 & 30.0 \\
\hline Smoker, up to 1 pack per day & 210 & 17.1 & 27.1 & 35.7 \\
\hline Smoker, more than 1 pack per day & 138 & 13.0 & 21.0 & 37.7 \\
\hline Total & $1198^{\mathrm{a}}$ & 14.0 & 21.3 & 31.1 \\
\hline Gynecologist appointments during previous year & & $(P<0.001)^{b}$ & $(P<0.001)^{b}$ & $(P<0.001)^{b}$ \\
\hline One or more & 839 & 8.5 & 12.7 & 16.3 \\
\hline None & 358 & 27.1 & 41.1 & 65.6 \\
\hline General practitioner appointments during previous year & & $(P<0.001)^{b}$ & $(P<0.001)^{\mathrm{b}}$ & $(P<0.002)^{\mathrm{b}}$ \\
\hline One or more & 773 & 11.4 & 18.1 & 27.8 \\
\hline None & 416 & 18.8 & 26.9 & 37.3 \\
\hline Type of health care of last gynecological appointment & & $(P<0.001)^{b}$ & $(P<0.001)^{b}$ & $(P<0.001)^{\mathrm{b}}$ \\
\hline Private/insurance & 531 & 6.6 & 12.2 & 20.3 \\
\hline Public sector & 642 & 19.2 & 27.7 & 38.2 \\
\hline Menopause & & $(P=0.08)^{\mathrm{b}}$ & $(P=0.8)^{\mathrm{b}}$ & $(P<0.16)^{\mathrm{b}}$ \\
\hline No & 849 & 12.8 & 21.5 & 29.8 \\
\hline Yes & 346 & 17.1 & 20.8 & 34.1 \\
\hline
\end{tabular}


TABLE 3. (Continued)

\begin{tabular}{|c|c|c|c|c|}
\hline Variable & $\begin{array}{c}\text { Number of } \\
\text { women }^{\mathrm{a}}\end{array}$ & $\begin{array}{l}\text { Prevalence of } \\
\text { lack of knowledge } \\
\text { about the test } \\
\text { (Percent) }\end{array}$ & $\begin{array}{l}\text { Prevalence of } \\
\text { never having } \\
\text { been tested } \\
\text { (Percent) }\end{array}$ & $\begin{array}{l}\text { Prevalence of not } \\
\text { having been tested } \\
\text { in the previous } \\
3 \text { years (Percent) }\end{array}$ \\
\hline $\begin{array}{l}\text { Age at first sexual intercourse (years) } \\
\geq 23 \\
20-22 \\
17-19 \\
14-16 \\
11-13 \\
\text { Did not answer }\end{array}$ & $\begin{array}{r}187 \\
224 \\
462 \\
257 \\
31 \\
37\end{array}$ & $\begin{array}{c}(P=0.002)^{\mathrm{c}} \\
9.1 \\
10.3 \\
13.6 \\
18.3 \\
25.8 \\
-\end{array}$ & $\begin{array}{c}(P=0.05)^{\mathrm{c}} \\
16.0 \\
21.0 \\
20.1 \\
23.3 \\
38.7 \\
-\end{array}$ & $\begin{array}{c}(P=0.03)^{c} \\
23.5 \\
30.4 \\
32.5 \\
31.1 \\
51.6 \\
-\end{array}$ \\
\hline $\begin{array}{l}\text { Number of risk factors for cervical cancer }{ }^{d} \\
0 \\
1 \\
2 \\
\geq 3\end{array}$ & $\begin{array}{r}486 \\
431 \\
228 \\
53\end{array}$ & $\begin{array}{c}(P<0.001)^{\mathrm{c}} \\
9.3 \\
14.4 \\
19.8 \\
30.2\end{array}$ & $\begin{array}{c}(P<0.001)^{\mathrm{c}} \\
16.5 \\
21.1 \\
27.6 \\
39.6\end{array}$ & $\begin{array}{c}(P<0.001)^{\mathrm{c}} \\
23.3 \\
32.3 \\
38.6 \\
62.3\end{array}$ \\
\hline Total & $1198^{a}$ & 14.0 & 21.3 & 31.1 \\
\hline
\end{tabular}

a Total observations differ between variables because of missing answers for some items.

${ }^{b}$ Wald test for heterogeneity (Poisson regression).

c Wald test for linear trend (Poisson regression).

d Smoking history, number of deliveries $>3$, number of sexual partners, schooling, age at first sexual intercourse.

restricted to women who had visited a gynecologist during the preceding year. In socioeconomic classes $\mathrm{A}$ and $\mathrm{B}$, only $11.9 \%$ of the women had not had a vaginal smear in the last 3 years; in classes $\mathrm{C}, \mathrm{D}$, and $\mathrm{E}$ the respective percentages were $29.2 \%, 45.4 \%$, and $64.3 \%$.

Regarding marital status, knowledge and coverage were lowest among widows, although the difference was statistically significant only for coverage (Table 3 ). There were no clear associations between knowledge or coverage and smoking status.

Significant differences were found for variables related to healthcare service usage. Women who visited a general practitioner or gynecologist within the 12 months prior to the interview were more likely to know about and to have had a Pap test
(Table 3). Among the women who consulted private sector gynecologists, $72.6 \%$ of all white women and $5.5 \%$ of all nonwhite women $(P=0.005)$ had had the test, whereas among users of public sector health care these percentages were $57.9 \%$ and $49.7 \%$, respectively $(P=0.05)$. Women whose last gynecologist appointment (at any time in the past) was with a private or health plan clinic were also more likely to know about and to have had the test (Table 3). When the analysis was restricted to women who had had an appointment with a physician within the previous year, the percentage of those who had not had the test in the preceding 3 years was $10.5 \%$ for private sector users and $21.9 \%$ for public sector users.

Our analysis of behavioral and biological variables related to sexual his- tory showed that menopause was not significantly associated with the outcomes we studied. Women with four or more deliveries and those who became sexually active at an early age were less likely to know about and to have had the test. Those with fewer than four sexual partners during their lifetime were less likely to know about the test, but this variable showed no association with actual Pap testing.

The number of risk factors identified for cervical cancer in each woman was inversely associated with her knowledge about the Pap test and coverage (Table 3).

Multivariate analysis for the main outcome-not having had the test during the previous 3 years-was based on Poisson regression. The variables age and skin color were kept in the first hierarchical level of the model of 
determination because both were significant, but menopausal status was excluded. In the second hierarchical level, socioeconomic level and schooling were kept in the model, but income and marital status were no longer significant after adjustment. In the third level, after allowing for variables from the first two levels that remained in the model, having been seen by a general practitioner or gynecologist during the preceding year remained significant (Table 4).

\section{DISCUSSION}

Although Papanicolaou smears are an effective tool for the early detection of cervical cancer, there are still questions as to whether Pap tests are being used appropriately by Brazilian women. The limited availability of epidemiological data hampers any attempt to evaluate population-wide coverage, and production data (number of tests performed) are not a reliable source of information because a small group of women may be taking the test repeatedly. Hence the need for population-based cross-sectional studies that make it possible to evaluate and monitor public policy implementation in this area. Further advantages of the cross-sectional design include the ability to obtain a probability sample, and greater speed and objectivity of data collection. Among the methodological aspects of the present study, we wish to highlight the low levels of loss and refusal, and the high similarity in the distribution of demographic and socioeconomic data between our sample and the municipal census (26) (data not shown). There are no data from Brazil on the quality of selfreports of Pap testing, but the international literature (27-28) suggests that overreporting may be a problem. This should be taken into account when the results presented here are interpreted.

Our data show that $14 \%$ of the women did not know about the test, and more than $99 \%$ did not know the recommended periodicity. A study conducted in a São Paulo gynecology hospital showed that $63 \%$ of the women with invasive cervical cancer had inadequate knowledge of the test (29). These results show that further efforts to educate women about Pap testing and cancer prevention are required.

We found that $78.7 \%$ of all women aged 25-59 years had had a Pap test at least once in their lifetime, and that $68.8 \%$ had been tested within the preceding 3 years. Therefore, the $80 \%$ coverage goal (with one test every 3 years) established by the National Program for the Prevention of Cervical Cancer (6) was not achieved, particularly if one considers that the present results may overestimate coverage because of selfreporting errors. Comparisons with data in other Brazilian studies show $64 \%$ test coverage in a 1995 INCA (National Cancer Institute) population survey of Pap testing performed at least once during a woman's lifetime. This number ranged, depending on conditions at each municipality, from $79 \%$ for capital cities to $56 \%$ for smaller cities (30). A random population-based study in São Paulo in 1987 found 69\% coverage for once-in-life testing and $60.8 \%$ coverage for the preceding 3 years (31). A 1991 case-control study in the same city found $67 \%$ coverage for once-in-life testing among control participants (32). Data from an earlier study of women 20 to 69 years old in the same city with the same methods as the present study showed $65 \%$ coverage for the preceding 3 years (33).

Pap tests performed at regular intervals on a large number of women will produce better results, with more lives saved, than their frequent repetition within restricted groups (34). Regular spacing of tests after two consecutive negative annual test results leads to lower costs with a minimal reduction in potential benefits and greater accessibility for all women (35).

An innovative aspect of the present study is our calculation of wasted resources caused by the unnecessary repetition of tests, as expressed by program focus. Only an estimated $20.6 \%$ of all tests performed during the year preceding the study were actually necessary according to program recommendations, waste being greater among higher socioeconomic levels. The 637 women who were tested during the 12 months prior to data collection represents more than one half of the target population of 1198 women in the program. The number of tests needed for all women once every 3 years would be roughly 450 tests yearly, considering the need to repeat the first test and those tests with inconclusive results. Therefore, the number of tests currently being performed in Pelotas would be more than enough to ensure $100 \%$ coverage of the population in an adequately organized program. This finding suggests inadequate care, resource leakage, and lack of an epidemiological basis for decision-making in the local healthcare system.

Data from the literature call attention to three determinants of social inequity in healthcare service usage: social class, race or ethnicity, and gender $(23,36)$. The present findings once again confirm social inequities present in Brazilian healthcare programs in terms of coverage. An interesting finding was that nonwhite women, despite attending gynecologist appointments as frequently as white women, received significantly less coverage in both public and private sectors. This suggests that healthcare professionals may be discriminating against nonwhite women. An earlier study in the same city showed that doctors (who are almost exclusively white) were less likely to carry out gynecological or breast examinations during antenatal care for black women than for white women (37). The reasons behind this possible discrimination deserve further investigation.

The present study showed highest levels of knowledge and coverage in women 35 to 44 years old, in agreement with the findings of other studies discussed above. The lower prevalence of knowledge and coverage among women 25 to 29 years old is noteworthy, since $75 \%$ of these women had had at least one gynecologist appointment during the year preceding the study. On the other hand, the 55to-59-year-old group, in which knowledge and coverage were lowest, were least likely to have been seen by a 
TABLE 4. Poisson multiple regression analysis of predictors of not having had a Pap test during the previous 3 years, adjusted for confounders, in women in Pelotas, Brazil, in 2002

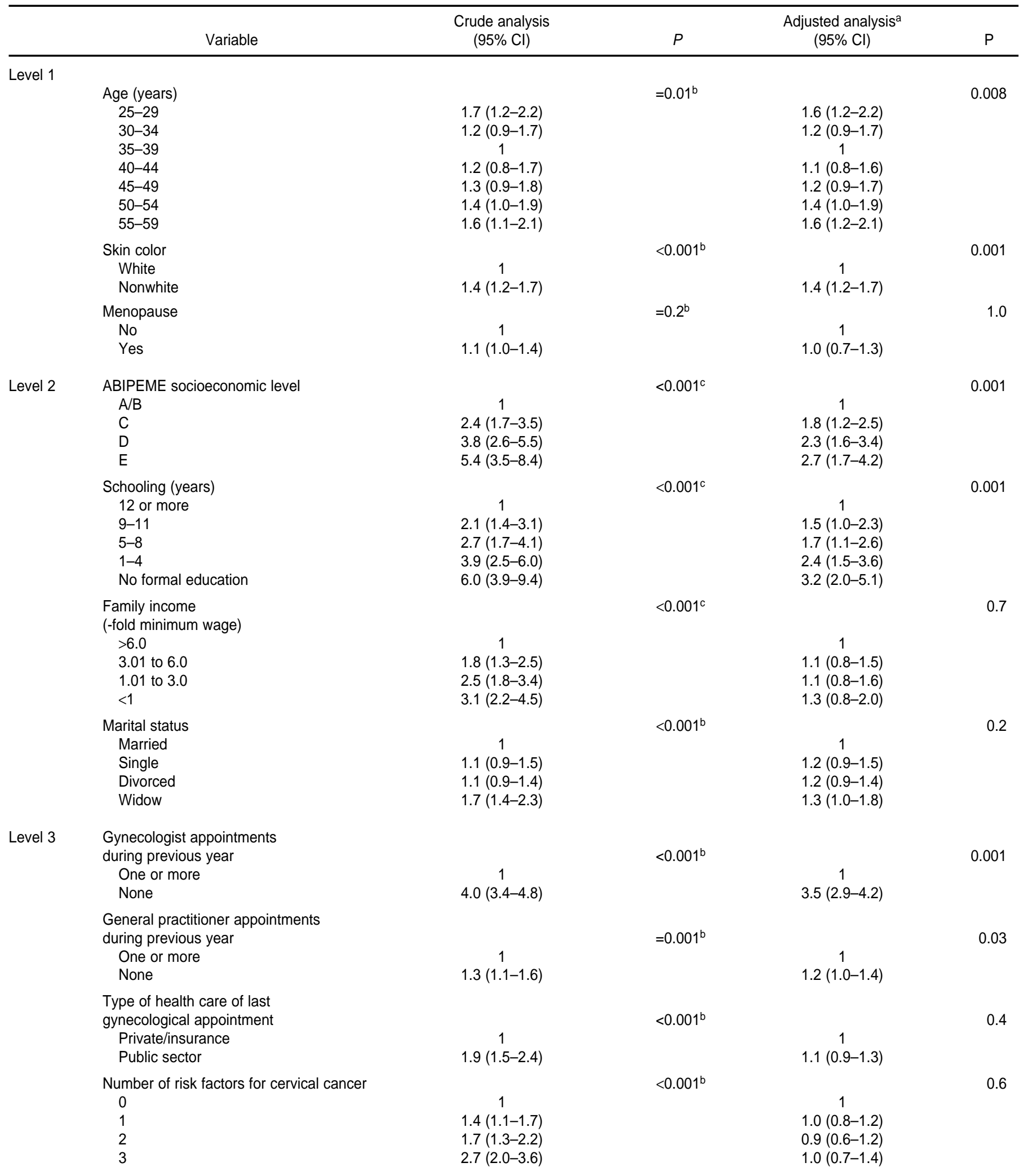

a Adjusted for others variables with $P<0.2$ in the same level or higher levels in the model of determination.

${ }^{b}$ Wald test for heterogeneity (Poisson regression).

${ }^{\mathrm{c}}$ Wald test for linear trend (Poisson regression). 
gynecologist $(61.1 \%)$ and most likely to have consulted a general practitioner $(80.7 \%)$ (data not shown). This preference may have contributed to the lower coverage in this age range.

Being seen by a physician increases the chance of becoming acquainted with and having the test: both specialist and general practitioner visits during the preceding year favored these two outcomes. On the other hand, approximately $30 \%$ of the women seen by a general practitioner, and $16 \%$ of those seen by a gynecologist, had not been tested in the previous 3 years, which indicates the large number of missed opportunities for prevention. The frequency of missed opportunities was significantly higher among black and poor women who were not tested despite having been seen by a gynecologist. The probability of not having the test was twice as high for women who were seen by public sector gynecologists during the preceding year $(21.9 \%)$ as for private sector users $(10.5 \%)$, which indicates that in this area, the public sector is not performing as well as the private sector. On the other hand, focus was similar between private (18.1\%) and public sector users $(23.8 \%)$, which indicates a lack of efficiency in both sectors.

Knowledge of the characteristics of the population studied here is impor- tant to identify the groups most vulnerable to cervical cancer, as a step toward better budget allocation and investments in higher levels of coverage in subgroups at greater risk. The crude estimates presented in Table 3 show that women with a greater number of risk factors were also the least likely to have been tested. The significance of this variable disappeared after adjustment, and is thus characterized here as a risk marker but not as a determinant of not having a Pap test. The women who needed the test most were those least likely to be tested, which once again demonstrates J.T. Hart's "Inverse Care Law" (38): healthcare availability is inversely proportional to one's need for it. In a study conducted in Mexico, the lowest coverage was also found for the population at highest risk (39).

Efforts to prevent cervical cancer in Brazil have entailed a combination of encouraging some (but not all) women to seek medical care services spontaneously with sporadic mass campaigns carried out in 1998 and 2002. These campaigns placed great emphasis on reaching high numbers of women without excluding those with a recent negative test. The combination of spontaneous care-seeking with indiscriminate campaigns has contributed to an excessive number of tests-which overburden the system- among low-risk women. The practice of frequent, unnecessary testing, on the other hand, is widespread in both the public and private sectors, as evidenced by the fact that $80 \%$ of the tests in both sectors were unnecessary. One can only speculate about the specific reasons for such inefficiency. In the private sector, where the professional is reimbursed by the patient or insurance company for every test performed, there is an obvious financial incentive for frequent, unnecessary testing (40). In the public sector, on the other hand, such financial mechanisms do not operate. Possible explanations may include the markedly lower levels of knowledge about the test among poor women (as shown in Table 3), as well as lower access to services where the test is carried out.

The recent expansion of the Family Health Program in Brazil entails the definition of a specific catchment area for each primary health facility, and monthly visits to all families by community health workers. In our view, this provides an excellent opportunity to correct the distortions we observed in our study by actively encouraging women to spontaneously seek appropriate care. It remains to be seen, however, whether the program will effectively improve Pap test coverage and focus.

\section{REFERENCES}

1. Parkin DM. Cancer Incidence in Five Continents. Vol. VII IARC Sci Publ. 1997;143:45-173.

2. Parkin DM, Bray FI, Devesa SS. Cancer burden in the year 2000. The global picture. Eur J Cancer. 2001; 37 Suppl 8:S4-66.

3. Abrão FS. Periodicidade e faixa etária na visão do Hospital A. C. Camargo. Rev Bras Cancerol. 1989;351/(2):36-7.

4. Brasil, Rio Grande do Sul, Secretaria Estadual da Saúde, Coordenadoria de Informações em Saúde. Sistema de informações em mortalidade. SIM 2000. Porto Alegre: Secretaria Estadual da Saúde; 2002.

5. Brasil, Ministério da Saúde, Secretaria Nacional de Assistência à Saúde, Instituto Nacional de Câncer-INCA. Estimativas da Incidência e Mortalidade por Câncer no Brasil. 2002. Rio de Janeiro: INCA; 2002.

6. Brasil, Ministério da Saúde, Secretaria Executiva, Controle do câncer do colo uterino: Pro- grama Nacional de Controle do Câncer do Colo Uterino. Brasília: Ministério da Saúde: 2001.

7. Barron BA, Richart RM. A statistical model of the natural history of cervical carcinoma based on a prospective study of 557 cases. J Natl Cancer Inst. 1968; 416:1343-53.

8. Papanicolaou G, Traut H. The diagnostic value of vaginal smears in carcinoma of the uterus. Am J Obstet Gynecol. 1941; 422:211-23.

9. Wilson JM, Jungner YG. Principles and practice of mass screening for disease. Bol Oficina Sanit Panam. 1968; 654:281-393.

10. Aareleid T, Pukkala E, Thomson H, Hakama M. Cervical cancer incidence and mortality trends in Finland and Estonia: a screened vs. an unscreened population. Eur J Cancer. 1993; 5:745-9.

11. Laara E, Day NE, Hakama M. Trends in mortality from cervical cancer in the Nordic coun- tries: association with organised screening programmes. Lancet. 1987; 18544:1247-9.

12. Hakama M. Potential contribution of screening to cancer mortality reduction. Cancer Detect Prev. 1993; 174-5:513-20.

13. Hakama M, Louhivuori K. A screening programme for cervical cancer that worked. Cancer Surv. 1988; 73:403-16.

14. Walton R. Cervical cancer screening programs. III. Components of a practical screening program for carcinoma of the cervix. Can Med Assoc J. 1976; 11411:1027-31.

15. Walton R. Cervical cancer screening programs. II. Screening for carcinoma of the cervix. Can Med Assoc J. 1976; 114(11):101326.

16. Walton R. Cervical cancer screening programs. I. Epidemiology and natural history of carcinoma of the cervix. Can Med Assoc J. 1976;114(11):1003-12. 
17. Nieminen P, Kallio M, Anttila A, Hakama M. Organised vs. spontaneous Pap-smear screening for cervical cancer: A case-control study. Int J Cancer. 1999; 831:55-8.

18. Hakama M. Cervical cancer: risk groups for screening. IARC Sci Publ. 1986; 76:213-9.

19. Lynge E, Poll P. Incidence of cervical cancer following negative smear. A cohort study from Maribo County, Denmark. Am J Epidemiol. 1986; 1243:345-52.

20. Dietz J, Prolla JC, Pohlmann PR, Loss JF, Da Costa LA, Daudt AW et al. Mortality from uterine cervix cancer in Rio Grande do Sul. Rev Assoc Med Bras. 1993; 393:146-50.

21. Mason JB, Habicht JP, Tabatabai H, Valverde V. Nutritional surveillance. Geneva: World Health Organization;1984.

22. ANEP. Associação Nacional de Empresas; Critérios de classificação econômica no Brasil. São Paulo: ANEP; 1996.

23. Lazcano-Ponce EC, Najera-Aguilar P, Buiatti E, Alonso-de-Ruiz P, Kuri P, Cantoral L et al. The cervical cancer screening program in Mexico: problems with access and coverage. Cancer Causes Control. 1997; 85:698-704.

24. Victora CG, Huttly SR, Fuchs SC, Olinto MT. The role of conceptual frameworks in epidemiological analysis: a hierarchical approach. Int J Epidemiol. 1997; 261:224-7.

25. Obwegeser JH, Brack S. Does liquid-based technology really improve detection of cervical neoplasia? A prospective, randomized trial comparing the ThinPrep Pap Test with the conventional Pap Test, including followup of HSIL cases. Acta Cytol. 2001; 455:709-14.
26. Brasil, Instituto Brasileiro de Geografia e Estatístico. Censo Demográfico 2000. Rio de Janeiro: Instituto Brasileiro de Geografia e Estatístico; 2001.

27. McPhee SJ, Nguyen TT, Shema SJ, Nguyen B, Somkin C, Vo P, et al. Validation of recall of breast and cervical cancer screening by women in an ethnically diverse population. Prev Med. 2002; 35(5):463-73.

28. McGovern PG, Lurie N, Margolis KL, Slater JS. Accuracy of self-report of mammography and Pap smear in a low-income urban population. Am J Prev Med. 1998; 14(3):201-08.

29. Brenna SM, Hardy E, Zeferino LC, Namura I. Knowledge, attitudes, and practices related to the Pap smear among women with cervical cancer. Cad Saude Publica. 2001;174:909-14.

30. Lopes ER, Rebelo MS, Abreu Ed, Silva VLdC, Eisenberg ALA, Lavor MF. Comportamento da população brasileira feminina em relação ao câncer cérvico-uterino [Behavior of feminine Brazilian population in relation to cervico-uterine cancer.] J Bras Ginecol. 1995; 10511/12:505-15.

31. Nascimento CMR, Eluf-Neto J. Cobertura do teste de Papanicolaou no município de São Paulo e caracteristicas das mulheres que realizaram o teste. Rev Panam Salud Publica. 1996; 1216:491-501.

32. Eluf-Neto J, Booth M, Munoz N, Bosch FX, Meijer CJ, Walboomers JM. Human papillomavirus and invasive cervical cancer in Brazil. Br J Cancer. 1994; 691:114-9.

33. Dias da Costa JS, D'Elia PB, Manzolli P, Moreira MR. Cytopathological test coverage in the city of Pelotas, Brazil. Rev Panam Salud Publica. 1998; 35:308-13.

34. Moss S. Bases epidemiológicas para avaliaçäo de diferentes programas de sreening [Epidemiologic bases to evaluation of different screening programs.] Rev Bras Cancerol. 1989; 351/2:55-8.

35. Espinosa HR. Periodicidade e faixa etária no exame de prevenção do câncer cérvicouterino. Rev Bras Cancerol. 1989; 351/2:49-54.

36. Olinto MT, Olinto BA. Race and inequality among women: an example in southern Brazil. Cad Saude Publica. 2000; 164:1137-42.

37. Barros FC, Victora CG, Horta BL. Ethnicity and infant health in Southern Brazil. A birth cohort study. Int J Epidemiol. 2001;30:1001-8.

38. Hart JT. The inverse care law. Lancet. 1971; 1(7696):405-12.

39. Lazcano-Ponce EC, Moss S, Cruz-Valdez A, de Ruiz PA, Martinez-Leon CJ, Casares-Queralt $S$ et al. The positive experience of screening quality among users of a cervical cancer detection center. Arch Med Res. 2002; 332:18692.

40. Mello CG. Saúde e Assistência Médica no Brasil. São Paulo: CEBES-HUCITEC; 1977.

Manuscript received 13 September 2003. Revised version accepted for publication on 16 July 2004

RESUMEN Objetivo. Determinar la cobertura y la concentración poblacional del tamizaje del cáncer cervicouterino (con la prueba de Papanicolaou) en una muestra poblacional en el Brasil.

\section{Cobertura y concentración poblacional de un programa para la prevención del cáncer cervicouterino en el sur del Brasil}

Métodos. Encuesta transversal por conglomerados en una muestra de 1740 mujeres de 20 años de edad o mayores con antecedentes de actividad sexual. Se recogió información acerca de las características sociales, demográficas y conductuales de estas mujeres, y sobre su familiaridad con la prueba de Papanicolau y la frecuencia con la que se la habían hecho.

Resultados. De las mujeres entre los 25 y 59 años de edad, en quienes se concentra el programa de tamizaje nacional, 78,8\% habían tenido como mínimo una prueba de Papanicolaou en su vida, y $68,8 \%$ habían tenido una en los últimos 3 años. Según las estadísticas del programa, 637 de las mujeres que indicaron haberse sometido a una prueba de Papanicolaou durante el último año, solamente 20,6\% necesitaban hacerse la prueba. Las demás no pertenecían al grupo de edad que se la debía hacer o se habían sometido a otra prueba hacía menos de 30 meses. Las mujeres de raza negra y las de bajos ingresos fueron las más propensas a no haberse hecho la prueba en los 3 años anteriores a la encuesta ( 41,7 y $64,3 \%$, respectivamente), y fueron precisamente las que tuvieron el riesgo más alto de padecer de cáncer cervicouterino $(62,3 \%$ en el caso de mujeres con tres factores de riesgo o más). La concentración de la prueba en ciertos grupos mostró una asociación directa con la posición socioeconómica.

Conclusiones. Los porcentajes de cobertura fueron parecidos a los notificados en otros estudios nacionales, pero este informe es el primero en examinar en quiénes se concentra el programa nacional. Hemos demostrado que 8 de cada 10 pruebas de Papanicolaou no eran necesarias. La cobertura sigue siendo demasiado pobre, a la luz de lo recomendado, en mujeres de estrato socioeconómico bajo y en las que están en mayor riesgo de padecer de cáncer cervicouterino. 